\title{
Laparoscopic pyeloplasty for pelvi-ureteric junction obstruction: Our single center experience
}

\section{Joshi R}

Robin Joshi, Associate Professor, Urology Unit, Department of Surgery, Kathmandu Medical College Teaching Hospital, Sinamangal, Kathmandu, Nepal.

\begin{abstract}
Background: Open pyeloplasty is considered as the gold standard for the treatment of pelvi-ureteric junction obstruction. Laparoscopic pyeloplasty has added advantages with equivalent success rate and low complication rate.

Objectives: The aim is to study our experiences in laparoscopic retroperitoneal and transperitoneal pyeloplasty.

Methodology: Sixty-five patients with pelvi-ureteric junction obstruction were included in the study. The study was conducted between October 2016 and May 2019 at Kathmandu Medical College Teaching Hospital. Pelvi-ureteric junction obstruction was evaluated by ultrasound and intravenous or computed tomography urography. Clinical history, hospital stay, complications, success rate and functional outcome were analyzed. Statistical analysis was done using the Statistical Package for the Social Sciences, version 20.0 (SPSS Inc., Chicago, IL, USA). A p-value $<0.05$ was taken as significant. Followup of the patients was carried out for six to twelve months clinically and radiologically.

Results: Laparoscopic transperitoneal pyeloplasty was performed in 27 males and 8 females. Retroperitoneal pyeloplasty was performed in 30 cases (20 males and 10 females). The mean age was $20.26 \pm 3.92$ years for all cases. Operative time was longer in retroperitoneal group. There were four conversions in retroperitoneal group. Mean hospital stay was longer in retroperitoneal group with significant $\mathrm{p}$-value $<0.001$. Success rate was almost similar in both groups with insignificant $\mathrm{p}$-value of 0.46 .

Conclusion: Transperitoneal laparoscopic pyeloplasty group achieved better results than retroperitoneal pyeloplasty group in terms of hospital stay, complication and drain placement but with almost similar success rate.
\end{abstract}

Key words: Pelvi-ureteric junction; Retroperitoneal pyeloplasty; Transperitoneal pyeloplasty.

DOI: https://doi.org/10.3126/jkmc.v8i4.32387

\section{INTRODUCTION}

$\mathrm{L}$ aparoscopic urologic surgery has been one of the most important developments in the last decade ${ }^{1,2}$. Most open urological services are now being replaced by minimally invasive surgery like laparoscopy and endourology. Laparoscopic pyeloplasty for pelvi-ureteric junction (PUJ) obstruction is one of them.

Laparoscopic pyeloplasty offers advantages to open surgery like magnified vision field, low morbidity with similar result and success rate $e^{1,2,3}$. The procedure also addresses various anatomic anomalies like crossing

Address for correspondence

Dr. Robin Joshi

Associate Professor, Urology Department

Department of Surgery

Kathmandu Medical College Teaching Hospital

Sinamangal, Kathmandu, Nepal

E-mail: robinjoshi@hotmail.com

ORCID: https://orcid.org/0000-0002-0284-4384 vessel, high insertion of ureter, redundant and extrarenal pelvis ${ }^{4,5}$.

Laparoscopic procedures may be technically demanding with some learning curve but it has advantages like reduced analgesic needs, hospital stay with early return to normal activity and better cosmesis compared to open surgery ${ }^{1,6}$. Laparoscopy pyeloplasty are performed in many centers around the world as published in many articles due to many advantages over open surgery.

Schuessler et al first described transperitoneal approach in 1993 and Janetscheket et al first reported their retroperitoneal pyeloplasty in $1996^{7,8}$. The procedure can be performed in both ways. Kathmandu Medical College provided laparoscopic urology services from 2009.

This study aims to compare morbidity and success rate of transperitoneal and retroperitonal pyeloplasty for PUJ obstruction. 


\section{METHODOLOGY}

This comparative study was conducted from October 2016 to May 2019 in Urology department at Kathmandu Medical College Teaching Hospital. Sixty five cases underwent laparoscopic pyeloplasty, 30 retroperitoneal and 35 transperitoneal methods respectively. Retroperitoneal pyeloplasty was performed on all early 30 cases till we started doing transperitoneally. After 30 cases of retroperitoneal pyeloplasty all other cases were subjected to transperitoneal approach. All patients were explained about the procedure and need of conversion to open surgery if condition arose. Informed and verbal consent was taken. All PUJ obstruction with or without stone were included in the study. Routine preoperative investigations were done and PUJ stenosis was assessed with ultrasound and intravenous or CT urography. Patients with bleeding disorder and multiple surgeries were excluded from the study. DTPA (Diethyletetraminepenta acetic acid) renal scan was not used as it is not readily available and most of the patients were unable to afford the cost of DTPA scan. All patients should be subjected to DTPA scan pre and post surgery whenever possible but this study is not available at Kathmandu Medical College.

Retroperitoneal approach was done in the first 30 cases after which we switched to transperitoneal approach as we gained experience in laparoscopy. Transperitoneal approach was more preferred due to better anatomy, more working space and easy laparoscopic suturing as compared to retroperitoneal approach.

Clinical history, presence of kidney stones, functional status of the affected kidney, hospital stay, complications, success rate and functional outcome were analyzed in the two variety of surgeries. Statistical analysis was done using Statistical Package for the Social Services,version 20.0(SPSS Inc., Chicago, IL, USA). The Mann-Whitney U test was used for analyses of $p$-value. A $p$ value $<0.05$ was considered as significant.

\section{SURGICAL TECHNIQUES:}

\section{Retroperitoneal Pyeloplasty (RP)}

The patient is placed in lateral position and first $10 \mathrm{~mm}$ port is created just below the tip of the $9^{\text {th }}$ rib. Space is created retroperitoneally by using finger dissection and then by port itself till the psoas muscle is clearly visible. Two other ports are inserted after adequate space creation retroperitoneally. Ureter is located medially to psoas muscle and traced cephalad to locate the PUJ stenosis. Most of the cases underwent Fenger's pyeloplasty for short PUJ stricture.

\section{Transperitoneal Laparoscopic Pyeloplasty (TP)}

The patient is placed in lateral position and first camera port $10 \mathrm{~mm}$ is placed just lateral to rectus sheath below umbilicus at the corresponding side using a Visiport (Figure 1). Next two $5 \mathrm{~mm}$ ports are placed accordingly after creation of pneumoperitoneum. Colon is reflected down after dissecting the white line of Todd and ureter sought. Ureter is dissected cephalad to the site of stenosis (Figure 2). Dismembered Anderson Hynes (AH) pyeloplasty and non-dismembered Fenger's pyeloplasty was performed according to the indication ${ }^{8}$ (Figure 3). Patients with short stricture were subjected to Fenger'spyeloplasty ${ }^{8}$.

Fenger's pyeloplasty being technically simpler was performed for short strictures in the absence of crossing vessels or if there was no high insertion of ureter. It is similar to Heineke- Mikulicz repair. An AH repair may be done for any type of PUJ obstruction and choice of surgery for crossing vessels ${ }^{6}$.

\section{TransmesocolicLaparoscopicPyeloplasty(TM)}

As for paediatric age group, TM was performed without mobilizing colon but instead through mesocolon. Mesocolon is approached at the site where fullness of renal pelvis is seen avoiding colonic vessels. $\mathrm{AH}$ or Fenger's pyeloplasty is done according to the indication.

\section{Follow up:}

Patients were followed up at six months and one year. Ultrasonography was done as the first initial test to see the status of affected kidney. CT urography was done to observe the improvement of functional result, grade of hydronephrosis and renal parenchyma. Free of symptoms was another variable taken into account to verify the success of the procedure. Most of the patients did not undergo DTPA scan due to unavailability and added cost of the test.

Success was defined by radiologic evaluation of resolution of obstruction and symptomatic relief during the follow-up visits. Postoperative renal ultrasonography was used to gather information on an improvement of renal parenchymal thickness and the grade of renal hydronephrosis. A system to grade upper tract dilatation or hydronephrosis $(\mathrm{HN})$ imaged by ultrasound was described by the appearance of the calices, renal pelvis and renal parenchyma as was described by Society for Fetal Urology (SFU) ${ }^{22}$. Follow up $\mathrm{CT}$ finding also was used to complement the finding of ultrasonography. 


\section{RESULTS}

Laparoscopic transperitoneal pyeloplasty was performed in 27 males and 8 females. Retroperitoneal pyeloplasty was performed in 30 cases (20 males and 10 females). Mean age of all patients was $20.26 \pm 3.92$ years. Right sided pyeloplasty was performed in 15, 2 and 18 cases for CR, TM and RP groups respectively. Likewise, left sided pyeloplasty was performed in 10,8 and 12 cases for CR,TM and RP group respectively. Pyelolithotomy (stone size range $1.8-3 \mathrm{~cm}$, mean $2.33 \mathrm{~cm}$ ) and pyeloplasty were done in two and three cases respectively for retroperitoneal and transperitoneal approach (Table 1).
Operative time ranged from 100 to 185 minutes with RP group taking longer time (120-185 minutes). Wound infection and prolonged urine leak was seen in retroperitoneal group and crossing vessels were noted in CR group not suspected pre-operatively. There were four conversions in retroperitoneal group due to difficult anatomy and peritoneal breach and none in the other group. Mean hospital stay was $2.4 \pm 0.57,2.1 \pm 0.31$ and 4.6 \pm 0.52 days respectively for $C R, T M$ and RP groups ( $p$-value $<0.05$ ). There was $2.85 \%$ failure rate and $97.15 \%$ success rate in TP group; $6.7 \%$ failure rate and $93.3 \%$ success rate in RP group ( $p$-value of 0.46 ) as shown in Table 2. Success was defined by symptomatic relief and radiological finding as described.

Table 1: Demographic data

\begin{tabular}{|c|c|c|c|c|}
\hline & $\begin{array}{l}\text { Lap transperitoneal approach } \\
\text { Colon reflecting (CR) }\end{array}$ & $\begin{array}{c}\text { Transmesocolic } \\
\text { (TM) }\end{array}$ & $\begin{array}{l}\text { Lap retroperitoneal } \\
\text { approach (RP) }\end{array}$ & p-value \\
\hline Number of patients ( $n$ ) & 25 & 10 & 30 & \\
\hline $\begin{array}{l}\text { Mean age } \pm S D \\
\text { years }(n=65,20.26 \pm 3.92)\end{array}$ & $21.56 \pm 2.06$ & $15.64 \pm 4.67$ & $22.73 \pm 3.81$ & \\
\hline \multicolumn{5}{|l|}{ Sex } \\
\hline Male & 20 & 7 & 20 & 0.34 \\
\hline Female & 5 & 3 & 10 & \\
\hline \multicolumn{5}{|l|}{ Location } \\
\hline Right & 15 & 2 & 18 & \multirow{2}{*}{0.356} \\
\hline Left & 10 & 8 & 12 & \\
\hline
\end{tabular}

Table 2: Comparative results of laparoscopic pyeloplasty

\begin{tabular}{|c|c|c|c|c|}
\hline & $\begin{array}{c}\text { Transperitoneal approach } \\
\text { CR }\end{array}$ & TM & $\begin{array}{l}\text { Retroperitoneal approach } \\
\text { (RP) }\end{array}$ & p-value \\
\hline $\begin{array}{l}\text { Operative time(min) } \\
\text { Range(100-185) }\end{array}$ & $110-160$ & $100-120$ & $120-185$ & \\
\hline \multicolumn{5}{|l|}{ Complications: } \\
\hline Prolonged urine leak & None & None & 3 & \\
\hline Wound infection & 1 & None & 2 & \\
\hline Ileus (> 3days) & None & None & 2 & \\
\hline Post operativebleeding & None & None & None & \\
\hline Pyelonephritis & 1 & None & None & \\
\hline Presence of crossing vessel & 4 & None & None & \\
\hline Conversion & None & None & 4 & \\
\hline $\begin{array}{l}\text { Drain placement(days) } \\
\text { Mean } \pm \text { SD }\end{array}$ & $2.2, \pm 0.51$ & $1.5 \pm 0.23$ & $4.03 \pm 0.47$ & \\
\hline Hospital stay(days) & & & & $<0.001(\mathrm{CR} / \mathrm{TM}$ \\
\hline $\operatorname{Mean}(2.31)$ & $2.4 \pm 0.57$ & $2.1 \pm 0.31$ & $4.26 \pm 0.52$ & vs RP) \\
\hline $\mathrm{SD}( \pm 0.49)$ & & & & $0.126(\mathrm{CR}$ vsTM) \\
\hline Success rate & $97.15 \%$ & & $93.3 \%$ & 0.46 \\
\hline
\end{tabular}




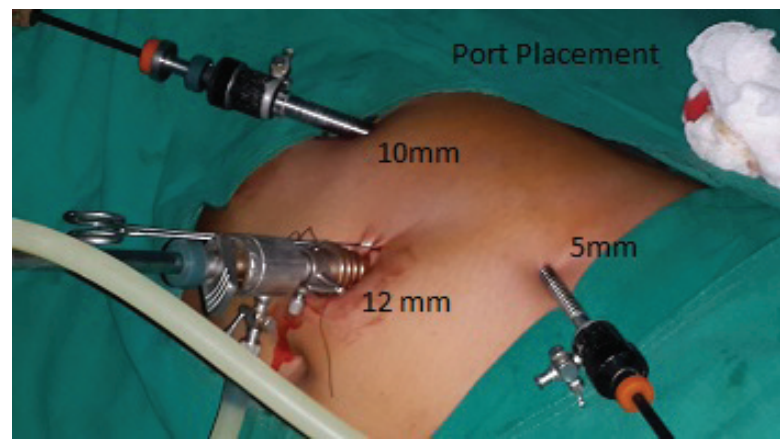

Figure 1: Portal placement

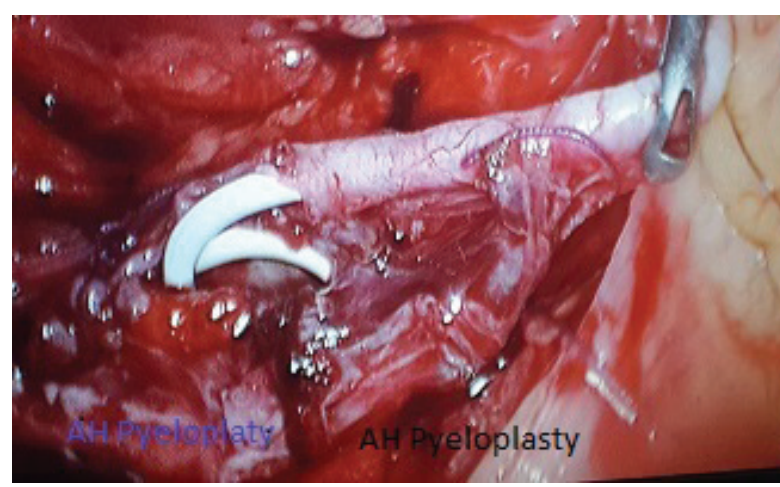

Figure 3: AH Pyeloplasty

\section{DISCUSSION}

Laparoscopic pyeloplasty may now be a preferred choice to open pyeloplasty. Many centers around the world have started robotic approach which is beyond the affordability in this part of the world. Comparison between open versuslaparoscopic and laparoscopic versus robotic approach have been published ${ }^{9,10,11}$.

Minimal invasive surgery is associated with lower morbidity, faster recovery and better cosmetic result. With increasing experience - understanding anatomy, minimizing complications and reducing the conversion rate to open are few other advantages. Recent studies have shown an overall success rate of more than $95 \%$ for primary PUJ obstruction ${ }^{12}$.

Our centre at Kathmandu Medical College started laparoscopy urology in 2009. Laparoscopic nephrectomy and retroperitoneal pyelolithotomy with pyeloplasty were performed then. Retroperitoneal approach needed longer learning curve to perform and to understand the anatomy due to few anatomical landmarks. In 2013; we published our early experience of retroperitoneal laparoscopic ureterolithotomy ${ }^{13}$. Retroperitonoscopy looked promising except for the learning curve and

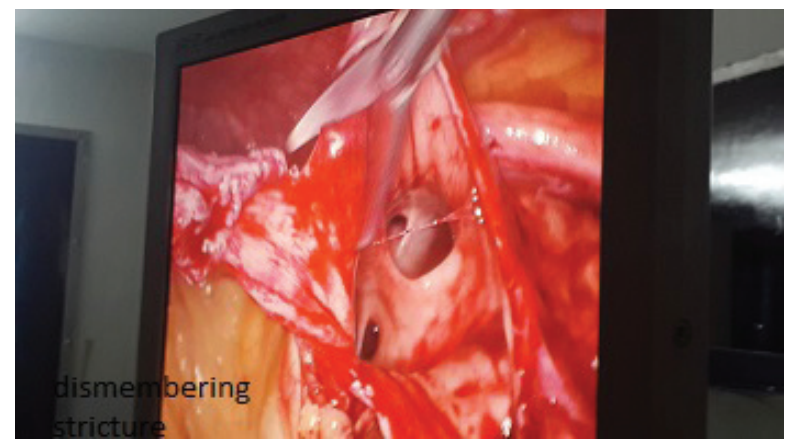

Figure 2: Dismembering stricture

long operative time. Retroperitoneal ureterolithotomy (upper), pyeloplasty, and pyelolithotomy and pyeloplasty were successfully done as we gained experience. The advantages we noticed were no intraperitoneal leak or urine spillage, direct access to PUJ and it could be performed in patients with previous history of laparatomy. Difficult anatomy, peritoneal breach and anteriorly placed ureter led to conversions. Three patients with re-stenosis were recorded. Two patients in RP group underwent open procedure correction and one patient in TP group was just managed with DJ stenting only for mild residual stricture as suggested by $C T$ urography. Transperitoneal approach was successfully performed as colon reflecting and transmesocolic approach for pyeloplasty ${ }^{14}$, sometimes combined with pyelolithotomy. The advantages we noticed were adequate space, familiar anatomy, crossing vessels and, anomalies like anteriorly placed ureter were easier to manage.

Though statistically not significant in overall success rate, our study was able to observe transperitoneal approach (colon reflecting and transmesocolic) easier and better than the retroperitoneal approach.There were more conversion rate, longer operative time, long learning curve in retroperitoneal pyeloplasty. Transmesocolic pyeloplasty were performed in paediatric age group for PUJ stenosis. In our study short hospital stay and morbidity were observed in Transmesocolic (TM) to colon reflecting approach(CR).TM approach has a shorter operative time without increasing morbidity as compared to CR group ${ }^{14,15,16,17}$.

In different studies, results were seen comparable in both retroperitoneal and transperitoneal approach in terms of morbidity and success rates ${ }^{18}$. Davenport et al reported overall success rate of $88 \%$ but the preferred approach was transperitoneal due to short learning curve and less conversion rate. Likewise, Canon SJ et al reported no 
major difference but preferred transperitoneal method because of larger working space for suturing, easier antegrade DJ stent placement ${ }^{19}$. Transperitoneal method provided shorter operative time and low conversion rate in a study conducted by WUY and team ${ }^{20}$.

Yeung et al reported their experience with retroperitoneal pyeloplasty. The longer time needed for the procedure was due to less working space making difficult anastomosis and antegrade stenting ${ }^{21}$.

During the study we were able to see the difference in both the approaches with clear advantage in

\section{REFERENCES}

1. Klingler HC, Remzi M, Janetschek G, et al. Comparison of openversus laparoscopic pyeloplasty techniques in treatment of ureteropelvicjunction obstruction. Eur Urol. 2003;44:340-5. [DOI]

2. Zhang X, Li HZ, Ma X, et al. Retrospective comparison of retroperitoneallaparoscopic versus open dismembered pyeloplasty forureteropelvic junction obstruction. J Urol. 2006;176:1077-80. [DOI]

3. Canes D, Berger A, Gettman MT, et al. Minimally invasive approachesto ureteropelvic junction obstruction. UrolClin NorthAm. 2008;35:425-39. [DOI]

4. Jarrett TW, Chan DY, Charambura TC, et al. Laparoscopic pyeloplasty:the first 100 cases. J Urol. 2002;167:1253-6. [DOI]

5. Turk IA, Davis JW, Winkelmann B, et al. Laparoscopic dismemberedpyeloplasty - the method of choice in the presence of anenlarged renal pelvis and crossing vessels. Eur Urol. 2002;42:268-75. [DOI]

6. O'Reilly PH, Brooman PJ, Mak S, et al. The long-term results ofAnderson-Hynes pyeloplasty. BJU Int. 2001;87:287-9. [DOI]

7. Schuessler WW, Grune MT, Tecuanhuey LV, et al. Laparoscopicdismembered pyeloplasty. J Urol. 1993;150:1795-9. [DOI]

8. Janetschek G, Peschel R, Altarac S, et al. Laparoscopic and retroperitoneoscopicrepair of ureteropelvic junction obstruction. Urology.1996;47:311-6. [DOI]

9. Umari, et al. Comparison of open and laparoscopic pyeloplasty in ureteropelvicjunction obstruction surgery:report of 49 cases.Arch Ital Urol Androl. 2011;83 (4):169-74. [PubMed]

10. Abdel-Karim AM, Fahmy A, Moussa A, Rashad $H$, Elbadry M, Badawy H, Hammady A. Laparoscopic pyeloplasty versus open pyeloplasty forrecurrent ureteropelvic junction obstruction in children.J Pediatr Urol. 2016 Dec;12(6):401.[DOI] transperitoneal group in terms of morbidity and laparoscopic maneuverability. Limitation of the study is the number of cases to compare between each other for better statistics.

\section{CONCLUSION}

Due to longer operative time, morbidity and long learning curve in retroperitoneal approach, transperitoneal approach can be considered the preferred approach. Success rate looks more promising in TM/CR group as compared to RP group.

11. Autorino R, Eden C, El-ghoneimi A, Guazzoni G, Buffi N, Peters CA, Stein RJ, Gettman M. Robotassisted and laparoscopic repair of ureteropelvic junctionobstruction: a systemic review and metaanalysis. Eur Urol. 2014 Feb;65(2):430-52. [DOI]

12. Jarrett TW, Chan DY, Charambura TC, et al. Laparoscopic pyeloplasty:the first 100 cases. J Urol. 2002;167:1253-6. [DOI]

13. Joshi R.Experience Sharing of Retroperitoneal Laparoscopic Ureterolithotomyfrom a Teaching Hospital. J Nepal Health Res Counc. 2013 Oct;11(25):279-82. [PubMed]

14. Singh SK, Kumar J, Sachin AN, Kapoor R, Srivastava A, Ansari MS. Prospective randomized study to evaluate the feasibility and outcomeof transmesocolic laparoscopic pyeloplasty and compare it with retrocoliclaparoscopic pyeloplasty in pediatric and adolescent patients.Indian J Urol. 2014Jul;30(3):2637. [DOI]

15. Sedláček J, Kočvara R, Molčan J, Dítě Z, Dvořáček J. Transmesocolic laparoscopic pyeloplasty in children: a standard approach for the left-side repair. J Pediatr Urol. 2010 Apr;6(2):171-7. [DOI]

16. Shadpour P, Nayyeri RK, Daneshvar R, Salimi H, Radfar $\mathrm{H}$. Prospective clinicaltrial to compare standard colon-reflecting with transmesocolic laparoscopic pyeloplasty. BJUInt. 2012 Dec;110(11):1814-8. [DOI]

17. Han HH, Ham WS, Kim JH, Hong CH, Choi YD, Han SW, Chung BH.Transmesocolic approachfor left side laparoscopic pyeloplasty: comparison with laterocolic approach in the initial learning period.Yonsei Med J. 2013 Jan 1;54(1):197-203. [DOI]

18. Davenport K, Minervini A, Timoney AG, Keeley FX Jr. Our experience with retroperitoneal and transperitoneal laparoscopic pyeloplasty for pelvi-ureteric junction obstruction.Eur Urol. 2005 Dec;48(6):973-7. [DOI] 
19. Canon SJ, Jayanthi VR, Lowe GJ.Which is betterretroperitoneoscopic or laparoscopic dismembered pyeloplasty in children?.J Urol. 2007 Oct;178:1791-5. [DOI]

20. Wu Y, Dong Q, Han P, Liu L, Wang L, Wei Q. Meta -analysis of Transperitoneal versus retroperitoneal approaches of laparoscopic pyeloplasty for ureteropelvic junctionobstruction. J laproendoscAdvSurg Tech A. 2012 Sep;22(7):658-62. [DOI]
21. Yeung CK, Tam YH, Sihoe JD, Lee KH, Liu KW. Reteroperitoneoscopicdismemberedpyeloplasty for pelviureteric junction obstruction in infants and children. BJUInt. 2001;87:509-12. [DOI]

22. Fernbach SK, Maizels M, Conway JJ.Ultrasound grading of hydronephrosis: introduction to the system used by the Society for Fetal Urology. PediatrRadiol. 1993;23:478-80. [DOI] 